The editors must exert more control on their printers to ensure a higher quality of production in the rest of the series. Absorption spectra should not overlap figure margins. The smudging and persistent variation on many pages of the ink density of chemical formulae and resonance structures of benzene should not have been allowed. and the quite inexplicable changes in type width give what must surely be an unintended significance to certain chemical reactions. These deficiencies are, however, chiefly in the first fifty pages of the text, and the general impression of type and figure lay-out of the volume is pleasing. Duncan Murchison

\section{Drug Data}

Sympathomimetic Drugs. By Domingo M. Aviado. (A Monograph in the Bannerstone Division of American Lectures in Anesthesiology.) Pp. xix + 613. (Thomas: Springfield, Illinois, July 1970.) $\$ 40$.

THIS book has been compiled for medical students, postgraduate students and doctors. It aims to assist doctors whether working in hospital or outside. Owing to the pruning of the time available for teaching pharmacology to medical students in Philadelphia, USA, the text deals less with general pharmacological principles arising from extensive courses in practical pharmacology, and more with clinical uses. Because of this pressure of circumstance, the author plunges the reader into the deep end, dealing in detail in chapters 1 to 5,7 , 8 and 10 with eight of the sympathomimetic drugs most commonly used in the US, namely epinephrine (adrenaline), norepinephrine (noradrenaline), ephedrine, metaraminol, mephentermine (mephenteramine), phenylephrine, methoxamine and isoproterenol (isoprenaline). To UK eyes, this list may seem somewhat strange, but it serves to emphasize that there are national differences when considering the emphasis placed on various drugs by the user communities. Chapters 6, 9 and 11 consider much wider spectra of drugs which might be used for raising blood pressure, cardiac stimulation, nasal decongestion and appetite suppression, vasoconstriction, vasodilation and relaxation of the bronchiolar muscle, against the detailed background information provided for each of the eight archetype sympathomimetic compounds. Each chapter is followed by a short summary of its main points and a substantial reference list.

This type of approach in a textbook would seem to be more useful to the British medical graduate than to the undergraduate, although the latter is invited to start by reading chapter 12 entitled "Pharmacology of Sympatho- mimetic Drugs" before turning to consider the foregoing chapters. Chapter 12 will enable him "to learn . . . the uses of sympathomimetic drugs in therapeutics". This phrase sums up the approach which is essentially directed towards the practical.

Chapter 12 deals in detail with the pharmacological anatomy and physiology of the sympathetic system before turning to consider $\alpha$ and $\beta$ receptors and $\alpha$ and $\beta$ blocking agents. The brief and rather superficial treatment of $\alpha$ and $\beta$ receptors is disappointing in a book running to over 600 pages, which might be expected to give a wide perspective of its subject. The $\beta$ blocking agent propranolol receives only passing reference on one page in its own right, and is mentioned on three other pages when referring to interactions with other drugs. Practalol receives no mention. The author, however, devotes much effort to grouping sympathomimetic drugs in Chapter 12 under four headings relating to a direct or indirect action on $\alpha$ and $\beta$ receptors stimulating the heart and influencing the blood vessels. or acting directly on $\alpha$ receptors (chiefly to constrict blood vessels) or on $\beta$ receptors (to dilate blood vessels and to relax smooth muscle). He goes on to provide examples of eight clinical situations in which sympathomimetic drugs may be required, ranging from an anaphylaxis, through cardiac stimulation, bronchodilatation and mydrias to combating shock. The practical approach shows up to great advantage here because the dose and route of administration of each of (often many) alternative drugs are given together with reference to other pages in the book on which the drug is treated in more detail. This type of readily available and systematized practical information is often missing from standard UK textbooks.

Professor Aviado has produced a substantial volume with many references which makes for an unusual presentation of sympathomimetic drugs. He has disciplined himself to take a strict approach severely directed to clinical applications. If the reader is prepared to use the book as a source of such information, he will find much to interest him. No fewer than 386 compounds are tabulated in the final chapter (13). These include the eight considered in detail and 53 in lesser detail in the preceding chapters. In spite of this long list, practalol has escaped inclusion. If the reader is, however, seeking a deep understanding of the mode of action of sympathomimetic drugs, then he will not find the volume helpful for this purpose but he will find the encyclopaedic list of compounds helpful in tracing the structure of less well known compounds.

The author, in his approach. poses the question "what sort of a book is required" by the medical student and graduate and others working in ancillary fields - a volume answering a host of practical questions or one blending an information source with an understanding of the underlying principles? $\mathrm{He}$ is courageous to undertake this task, which will stimulate us to consider our values and requirements in textbooks in this field with particular reference to the growing needs in the UK for extensive educational programmes for postgraduate medical practitioners, young and old alike.

J. P. Quilliam

\section{Probing the Brain}

Physiological Psychology. By Peter M. Milner. Pp. $x+531$. (Holt, Rinehart and Winston: New York and London, 1970.)

THE view that the royal road of advance in physiological psychology involves finding out what happens to an animal's behaviour when one prods around inside its head is widespread. Peter Milner, whose book is the most recent addition to texts on the subject, is evidently of this persuation and states that "the logic of probing the nervous system for cues (sic) to behaviour is almost universally accepted".

The author explains that he is interested in understanding behaviour in the same way that it is possible to understand a motor car or a radio. The difficulty about the probing approach--.. of which he approves--is that valuable insights about the workings of a radio are not gained by observing its behaviour while thrusting a hot soldering iron into its innards. Even poking about with the terminals of a voltmeter is not going to be much good if we do not already understand how the radio works and what to look for. Comprehending the principles upon which brain mechanisms operate seems to require techniques (such as simulation) which are of a quite different kind.

What one gets from probing is the strong impression that the brain has something to do with behaviour, together with a set of notions about particular parts of the brain being concerned in particular aspects of behaviour. Though much of physiological psychology is still at this stage, the time has come to get away from this kind of approach. Milner makes a modest attempt to do so in that, within the contexts of sensory and motivational systems, he gives a small amount of space to the discussion of possible mechanisms and models. Unfortunately, he does not take this nearly far enough, either in extent or rigour.

This book is one of half a dozen or so such texts available, and is not a bad example of its kind. The author tra- 